preciable amount by the ammonium chloride wash, as was determined by the A. O. A. C., ${ }^{1}$ and the double salt remaining after its use in all cases appeared perfectly pure when examined under a microscope. It may easily be seen in comparing this with the official method that at least two filtrations, and the time and annoyance of driving off ammonium salts are saved. It has also been ascertained that if ordinary care be taken in the laboratory: no ammonium salts will be absorbed." The following table wili show how duplicates agree by this method:

\begin{tabular}{|c|c|c|c|}
\hline \multirow{2}{*}{$\begin{array}{l}\text { Air-dried } \\
\text { sample. }\end{array}$} & \multirow{2}{*}{$\begin{array}{l}\text { Amount } \\
\text { taken. } \\
\text { Grams. }\end{array}$} & \multicolumn{2}{|c|}{ Per cent. $\mathrm{K}$. } \\
\hline & & I. & 2. \\
\hline Oats $\ldots \ldots \ldots \ldots \ldots$ & . 2 & 0.506 & 0.506 \\
\hline 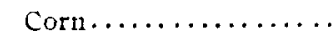 & - 2 & $0.3^{15}$ & 0.311 \\
\hline Gluten meal......... & . 2 & 0.245 & 0.232 \\
\hline Oil meal $\ldots \ldots \ldots \ldots$ & - 2 & I. 233 & I. 220 \\
\hline Clover hay .......... & . 3 & 1.463 & I. 452 \\
\hline Corn silage...$\ldots \ldots \ldots$ & $\cdot 3$ & 0.809 & 0.798 \\
\hline Dung No. I $\ldots \ldots \ldots \ldots$ & . 3 & 0.485 & 0.488 \\
\hline Dung No. $2 \ldots \ldots \ldots$ & . 3 & 0.510 & 0.515 \\
\hline Dung No. $3 \ldots \ldots \ldots$ & . 3 & $0.58_{5}$ & 0.588 \\
\hline Dung No. $4 \ldots \ldots \ldots$ & - 3 & 0.477 & 0.473 \\
\hline
\end{tabular}

\title{
NOTE ON A METHOD OF DETERMINING SMALL QUAN- TITIES OF MERCURY.
}

B3 ThEONORE WILLIAM RICHARDS AND SIDNEY KENT SINGER. Releived Jatuary 16,1904

IN A recent investigation, Richards and Archibald ${ }^{3}$ had occasion to detect and estimate small quantities of mercury in the presence or cadmium. The different solution-tensions of these metals at once suggested an electrolytic procedure, but it was found more convenient to conduct the separation with the help of a third metal than with the application of outside electromotive force. Among the many other metals which might have been chosen, copper was selected as the most suitable to precipitate the mercury; because, although its solution-potential is over 0.4 volt greater than that of mercury, it is nevertheless so hard to

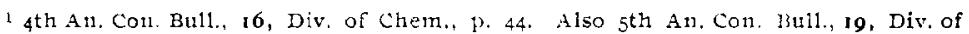
Chem., p. 39 .

2 It should be noted that the ammonium double salt is soluble in the Iindo-Gladding wash.

Proc. Am. Acad, 38,347 (190z): Ziscir. phys. Chem., 40, 335 (1902) (?). 
dissolve as to be reasonably permanent in aqueous solutions. Since cadmium has a far greater solution-tension than copper ( 0.75 volt) there could be no danger of contaminating the mercury with cadmium.

Preliminary experiments, made by these investigators, indicated that this method, generally familiar as a common qualitative test for mercury, might also be a useful and convenient one for the quantitative determination of small quantities of the liquid metal; accordingly, the present analyses were undertaken in order to test its accuracy.

Our experiments were made as simply as possible by suspending coils of copper wire, about $1.5 \mathrm{~mm}$. in diameter, in $15 \mathrm{cc}$. of each of the several solutions containing mercury. The metallic surface had been carefully polished, and cleaned with alkali, acid and water in succession. The coiled wire was found to give better results than the gauze, probably because of the difficulty of cleansing adequately the interstices caused by overlapping wires. When the mercury had been deposited on the copper, the coils were washed with water and alcohol, and dried in a desiccator over calcium chloride. After weighing this amalgamated coil, it was ignited gently in a stream of hydrogen, and then weighed once more. The loss of weight indicated the amount of mercury.

Preliminary experiments pointed toward several necessary precautions. In the first place, it was found that mercurous sulphate or basic sulphates were liable to appear if much sulphuric acid was present, hence nitrates are preferable. An excess of acid is not advisable, because of its independent action on the copper coil. Again, it was found that traces of copper were volatilized with the mercury if the temperature of the ignition was allowed to rise much above the boiling-point of the more volatile metal $\left(350^{\circ}\right)$. Although not necessary, it was found convenient to use two coils, one to take out the great bulk of the mercury, and the other to remove the last traces. As will be seen from the following table, the greater part of the mercury is precipitated in a short time, the remainder requiring many hours. In the analyses recorded below, a solution of mercuric nitrate, containing a known amount of mercury, was used for analysis. 
PRECIPITATION OF MERCURy BY COPPER.

\begin{tabular}{|c|c|c|c|c|c|c|c|}
\hline $\begin{array}{c}\text { No. } \\
\text { of } \\
\text { analysis. }\end{array}$ & $\begin{array}{l}\text { Time, } \\
\text { first } \\
\text { coil. } \\
\text { Hrs. }\end{array}$ & $\begin{array}{c}\text { Time, } \\
\text { second } \\
\text { coil. } \\
\text { Hrs. }\end{array}$ & $\begin{array}{l}\text { Weight of } \\
\text { Hg. Grst } \\
\text { coil. } \\
\text { Gram. }\end{array}$ & $\begin{array}{l}\text { Weight of } \\
\text { Hg, second } \\
\text { coil. } \\
\text { Gram. }\end{array}$ & $\begin{array}{l}\text { Total } \\
\text { Hg } \\
\text { found. } \\
\text { Gram. }\end{array}$ & $\begin{array}{c}\text { Total } \\
\text { Hg } \\
\text { takell. } \\
\text { Gram. }\end{array}$ & $\begin{array}{l}\text { Error. } \\
\text { Gram. }\end{array}$ \\
\hline I & 2 & 2 & 0.0297 & 0.0028 & 0.0325 & 0.0332 & -0.0007 \\
\hline 2 & 3 & 2 & 0.0308 & 0.0015 & 0.0323 & 0.0332 & -0.0009 \\
\hline 3 & 4 & 2 & $0.03 \mathrm{II}$ & 0.0014 & 0.0325 & 0.0332 & -0.0007 \\
\hline 4 & 5 & 2 & 0.0320 & 0.0006 & 0.0326 & 0.0332 & -0.0006 \\
\hline 5 & 6 & 2 & 0.0318 & 0.0009 & 0.0327 & 0.0332 & -0.0005 \\
\hline 6 & 7 & 2 & 0.0326 & 0.0003 & 0.0329 & 0.0332 & -0.0003 \\
\hline 7 & 18 & 2 & 0.0328 & 0.0003 & $0.03 .3 \mathrm{I}$ & 0.0332 & --0.0001 \\
\hline 8 & I 8 & 2 & 0.0329 & $0.000 \mathrm{I}$ & 0.0330 & 0.0332 & -0.0002 \\
\hline
\end{tabular}

This table shows that during two hours 0.9 of the mercury had been precipitated. The introduction of a second fresh coil for two hours more took out four-fifths of the remaining mercury, while leaving the first coil in the solution for the same additional time precipitated half of this residue; these data demonstrate the efficiency of the second coil. Experiment, kindly made for us by Mr. G. F. Behr, Jr., showed that amalgamated copper has essentially the same solution-tension as pure copper, hence the more tardy action of the already analgamated copper was due merely to the hindering effect of the film of liquid metal in which the copper must dissolve before ionizing. In seven hours, even a single coil precipitated all but 0.6 milligram of mercury, the removal of this last portion requiring more than double the time. The best results would probably be obtained by allowing the first coil to remain four of five hours in the solution, and the second coil to remain there for twenty hours. Stirring would probably accelerate greatly the leposition, and this might be most readily effected by causing the copper coil to rotate. The efficiency of rotating cathodes and anorles in electrolysis has been demonstrated by several experimenters, and this is a parallel case.

HARTARD CNIVERSTT,

December, 1903 .

\section{SOME PROPERTIES OF PHENYL ETHER.}

BY AIFRHI N. COOK.

Received fanunty 4, 2904.

Althovan many derivatives of phenyl ether have been prepared, the properties of the mother substance have not heretofore 